\title{
PERAN PUSTAKAWAN UNTUK MENARIK MINAT BACA DI PERPUSTAKAAN UMUM KECAMATAN SEMANDING - TUBAN
}

\author{
Suhernik ${ }^{1}$, Siti Uswatun Khasanah ${ }^{2}$ \\ ${ }^{1}$ Perpustakaan Universitas Airlangga \\ ${ }^{2}$ Mahasiswa Program S1 Ilmu Perpustakaan, Fakultas Ilmu Sosial dan Ilmu Politik, \\ Jurusan Perpustakaan, Universitas Terbuka \\ E-mail: uswatunkhasanah@gmail.com
}

\begin{abstract}
ABSTRAK
Perpustakaan adalah sebuah tempat atau wadah yang memberikan informasi kepada pelanggan atau pengguna perpustakaan. Dalam hal ini yang menjadi tempat penelitian yang dilakukan peneliti adalah perpustakaan umum kecamatan Semanding yang bertujuan untuk mengetahui peran pustakawan dalam meningkatkan minat baca di daerah Semanding ini. Dengan didirikannya perpustakaan yang masih dibilang sangat baru ini dapat memberikan dampak positif pada masyarakat sekitarnya. Hasil dari penelitian ini bahwa peran pustakawan di perpustakaan umum kecamatan Semanding telah melakukan inovasi dengan mengadakan lomba-lomba untuk menarik minat anak untuk datang ke perpustakaan. Serta minat baca yang ada di perpustakaan umum kecamatan Semanding ini masih rendah karena koleksinya masih kurang mendukung pembelajaran anak sekolah. Saran peneliti untuk perpustakaan umum ini dikembangkan lagi koleksinya agar lebih lengkap, pustakawan yang ada harus lebih kreatif untuk menarik minat baca di masyarakat sekitar Semanding dan pustakawan hendaknya memberikan rasa nyaman serta mengatur koleksinya agar pengguna perpustakaan tidak kesulitan dalam mencari bahan pustaka.
\end{abstract}

Kata kunci: minat baca, pustakawan, perpustakaan umum kecamatan Semanding

\section{PENDAHULUAN}

\section{Latar Belakang}

Indonesia ini merupakan negara yang memiliki penduduk terbesar keempat di dunia akan tetapi dalam minat baca penduduk Indonesia masih sangat rendah dibandingkan dengan negara lain, maka sekarang ini banyak didirikan perpustakaan baik di desa maupun di kota untuk menunjang atau memperbaiki minat baca masyarakatnya. Dari koran yang telah saya baca di tahun 2012 bahwa tingkat nilai indeks membaca di Indonesia kurang lebih 0.001. Dibandingkan dengan Amerika, Singapura atau negara lain Indonesia masih di tingkat terbawah. Berdasarkan survei yang dilakukan UNESO, budaya membaca masyarakat Indonesia ada di urutan 38 dari 39 negara dikawasan ASEAN, jadi tingkat budaya baca di Indonesia masih sangat lah minim dan rendah. ${ }^{2}$

Sedikit sejarah didirikannya perpustakaan umum kecamatan Semanding ini berawal dari perpustakaan daerah kabupaten Tuban yang mengadakan literasi dengan mendirikan sebuah Perpustakaan umum untuk minat baca masyarakat Semanding yang berdiri pada tanggal 12 Desember 2018, terhitung masih sangat baru untuk ukuran perpustakaan umum, pada awalnya sebelum didirikan perpustakaan umum dahulu tempat itu adalah puskesmas yang telah lama tidak berpenghuni dan kemudian Dinas Perpustakaan ada inisiatif untuk mendirikan perpustakaan untuk minat baca dan merubah masyarakat agar senang dengan membaca dan agar tempat itu lebih berguna dari sebelumnya. Maka dibangunlah perpustakaan kecamatan dan inilah perpustakaan pertama yang ada di kecamatan Semanding yang akan membawa perubahan kepada warga kecamatan Semanding khususnya dan untuk warga kecamatan lain umumnya. Di perpustakaan umum kecamatan Semanding ini untuk koleksi bacaan serta buku-buku nya masih sedikit belum lengkap serta penataannya kurang rapi. Di setiap harinya pengunjungnya pun masih sepi mungkin hanya beberapa anak saja yang mengunjungi 
perpustakaan umum tersebut. Sehingga minat baca di daerah kecamatan Semanding sangatlah minim atau masih sangat jauh dari rata-rata.

Peran pustakawan adalah sebagai kamus informasi atau seseorang yang bertanggung jawab atas perpustakaan tersebut dan bisa menjawab pertanyaan pengunjung baik dalam segi koleksi atau yang lainnya. Dalam perpustakaan umum kecamatan Semanding pustawakannya ramah akan tetapi jika ditanya jawabannya kurang detail serta masih kurang merangkul pengunjungnya agar mengerti bagaimana cara mencari buku yang diperlukan atau sebagainya. Petugas perpustakaannya ada 3 orang yang terdiri dari 2 orang diambil dari dinas kearsipan dan 1 orang dari dinas perpustakaan. Untuk pengunjungnya yang banyak dari kalangan anak-anak serta remaja yang datang untuk membaca buku ataupun hanya untuk memanfaatkan wifi atau internetnya saja.

\section{Rumusan Masalah}

Sesuai dengan latar belakang di atas maka dapat di simpulkan bahwa masalah yang ada:

1. Bagaimanakah peran pustakawan terhadap minat baca di perpustakaan umum kecamatan Semanding?

2. Faktor-faktor apa saja yang mempengaruhi minat baca di perpustakaan umum kecamatan Semanding?

\section{Hipotesis Penelitian}

Peran pustakawan di perpustakaan umum kecamatan Semanding dapat menarik minat baca masyarakat setempat mulai dari pelajar sampai masyarakat umum, sehingga banyak yang datang untuk membaca dan mencari buku serta informasi di perpustakaan umum tersebut.

\section{Tujuan}

Sesuai dengan rumusan masalah yang ada, maka yang ingin dicapai sebagai berikut:

1. Untuk mengetahui peran pustakawan terhadap minat baca di daerah kecamatan Semanding agar semakin meningkat

2. Untuk mengetahui faktor yang mempengaruhi minat baca di perpustakaan umum kecamatan Semanding

\section{TINJAUAN PUSTAKA}

\section{Minat Baca}

Minat dan baca mempunyai pengertian sendiri-sendiri. Minat adalah suatu perpaduan keinginan dan kemauan yang bisa berkembang jika ada motivasi. Sedangkan membaca adalah sebuah kegiatan fisik dan mental. Melalui membaca, kita akan mendapatkan informasi dan pengetahuan bagi kehidupan. ${ }^{3} \mathrm{Jadi}$, minat membaca adalah suatu perhatian yang kuat dan mendalam yang disertai dengan perasaan senang terhadap kegiatan membaca hingga dapat membuat seseorang untuk membaca dengan kemauannya sendiri. Maka secara garis besar minat membaca bertujuan untuk menumbuhkan dan mengembangkan suatu lingkungan yang menyukai kegiatan membaca dan menjadikan suatu masyarakat baca dengan penekanan lingkungan baca pada semua jenis bacaan.

Menurut Instruksi Presiden nomor 15 tahun 1974, pada tanggal 13 September 1974, di pasal 4 bahwa yang dimaksud dengan pembinaan secara menyeluruh itu mencakup pada perencanaan, pengaturan, pengendalian, dan penilaian kegiatan yang saling berhubungan dengan suatu sistem. Tujuan awal dari pembinaan minat baca adalah untuk menciptakan masyarakat membaca dengan menekankan pada penciptaan lingkungan membaca untuk semua jenis bacaan pada semua masyarakat. Menurut Keputusan Menteri Dalam Negeri nomor 9 tahun 1988 dan Instruksi Menteri Dalam Negeri nomor 21 tahun 1988, perpustakaan umum - termasuk perpustakaan desa - mempunyai fungsi: a) melestarikan bahan pustaka dan informasi; b) mengumpulkan dan mengolah bahan pustaka dan informasi; c) mengatur dan menggunakan kembali bahan pustaka dan informasi sebagai pusat kegiatan belajar, pelayanan informasi dan penelitian serta menumbuhkan minat dan kebiasaan membaca bagi semua masyarakat. Berdasarkan keputusan menteri dalam negeri tersebut, perpustakaan sebagai sarana untuk memenuhi kebutuhan informasi masyarakat agar mencapai tujuan untuk mencerdaskan kehidupan bangsa. Salah satu usaha yang bisa dicapai melalui pembinaan minat baca. ${ }^{4}$

\section{Pustakawan}

Pustakawan adalah tenaga profesional yang mempunyai tugas sebagai mengelola perpustakaan, mengorganisasikan materi perpustakaan agar dapat di dayagunakan oleh pengguna. ${ }^{5}$

\section{Standar Kompetensi Pustakawan}

Pustakawan ialah suatu tenaga profesi, oleh karena itu seorang pustakawan harus profesional dalam bekerja di bidangnya. Untuk mendapat predikat profesional, seharusnya seorang pustakawan harus mempunyai sertifikat keahlian yang bisa didapatkan dengan mengikuti 
ujian sertifikasi dan dinyatakan lulus. Sertifikasi Pustakawan yang ada di Indonesia dilaksanakan oleh Badan Nasional Sertifikasi Profesi (BNSP) yang ini bertanggung jawab kepada Presiden. Dalam pelaksanaan Sertifikasi Pustakawan BNSP menunjuk Perpustakaan Nasional RI sebagai LSP dan dalam mengefektifkan pelaksanaan Sertifikasi Pustakawan di seluruh Indonesia lembaga LSP Perpustakaan Nasional RI membentuk Tempat Uji Kompetensi (TUK) sebagai tempat pelaksanaan uji kompetensi sertifikasi pustakawan di Indonesia. ${ }^{6}$

Seperti dalam pekerjaan terdapat jenjang tingkatan, demikian juga kompetensi memiliki penjenjangan menurut tingkat kesukaran. Dari kompetensi ini dapat diturunkan pelatihan apa yang dapat membekali pustakawan tersebut serta kompetensi ini juga dipakai untuk menguji keberhasilan dari pelaksanaan pelatihan ini.

\section{Kode Etik Pustakawan Indonesia}

Pustakawan merupakan seseorang yang berkarya secara profesional di bidang perpustakaan, yang sadar akan pentingnya sosialisasi profesi Pustakawan pada masyarakat luas, serta diperlukan juga menyusun etika sebagai pedoman kerja.

Dalam keterbukanya informasi, diperlukan sebuah kebebasan intelektual dan perluasan akses informasi bagi kepentingan masyarakat. Pustakawan harus ikut serta dalam melaksanakan kelancaran informasi yang bertanggung jawab untuk keperluan generasi sekarang dan masa depan. Pustakawan harus berperan aktif dalam melakukan tugas sebagai pembawa perubahan dan meningkatkan kecerdasan masyarakat untuk mengantisipasi perkembangan dan perubahan di masa yang akan datang.

Prinsip yang tertuang dalam Kode Etik ini merupakan kaidah umum Pustakawan Indonesia dengan Kewajiban Pustakawan yang tertuang pada bab I, yaitu:

a. Kewajiban Kepada Bangsa dan Negara.

Seorang pustakawan bisa menjaga martabat dan moral serta mengutamakan pengabdian dan tanggung jawab kepada instansi tempat bekerja, Bangsa dan Negara

b. Kewajiban Kepada Masyarakat:

- Pustakawan melindungi kerahasiaan dan privasi menyangkut informasi yang ditemui atau dicari dan bahan pustaka yang diperiksa atau dipinjam pengguna atau pengunjung pepustakaan.

- Pustakawan harus berusaha menciptakan nama baik perpustakaan yang baik dan nyaman dimata masyarakat.
- Pustakawan melaksanakan pelayanan perpustakaan dan informasi kepada setiap pengguna secara cepat, tepat, dan akurat sesuai dengan prosedur pelayanan perpustakaan.

- Pustakawan ikut ambil bagian dalam kegiatan yang diselenggarakan masyarakat dan lingkungan tempat bekerja, terutama yang berkaitan dengan pendidikan, usaha sosial dan kebudayaan.

c. Kewajiban Kepada Profesi

- Pustakawan melaksanakan Anggaran Dasar dan Anggaran Rumah Tangga Ikatan Pustakawan Indonesia dan Kode etik Pustakawan Indonesia.

- Pustakawan menghormati hak milik intelektual yang berkaitan dengan bahan yang ada di perpustakaan dan informasi yang ada.

- Pustakawan memegang prinsip kebebasan intelektual dan menjauhkan diri dari usaha sensor sumber bahan perpustakaan dan informasi.

- Kewajiban Kepada partner kerja Pustakawan memperlakukan rekan bekerja berdasarkan pada sikap saling menghormati, dan adil kepada rekan.

d. Kewajiban Kepada Pribadi:

- Pustakawan menjauhkan diri dari sesuatu yang menyalahgunakan fasilitas perpustakaan untuk kepentingan pribadi, rekan bekerja dan pengguna tertentu.

- Pustakawan berusaha memperluas pengetahuan dan kemampuan diri serta profesionalism.

- Pustakawan dapat memisah-misahkan antara kepentingan pribadi dan kegiatan profesional kepustakawanan.

Kemudian yang tertuang dalam bab II berisi sebuah Sanksi yang di berikan kepada:

Pustakawan yang melanggar AD/ART IPI dan kode etik pustakawan Indonesia akan dikenai sanksi yang sesuai dengan pelanggarannya, dan dapat diajukan ke Dewan Kehormatan Ikatan Pustakawan Indonesia untuk keputusan lebih lanjutnya. ${ }^{7}$

\section{Perpustakaan}

Menurut Sulistyo Basuki perpustakaan merupakan sebuah ruangan atau gedung yang digunakan untuk menyimpan buku dan terbitan lainnya untuk disimpan menurut data susunan tertentu yang memudahkan pembaca untuk mencarinya (Sulistyo, Basuki 1991). ${ }^{8}$

Berdasarkan Undang-Undang No.43 Tahun 2007 tentang perpustakaan pada Bab I Pasal 1, disebutkan bahwa yang dimaksud dengan perpustakaan ialah institusi pengelola koleksi karya tulis, cetak, dan rekam 
secara profesional dengan sistem yang baku guna untuk memenuhi kebutuhan pendidikan, penelitian, informasi, dan rekreasi para pemustaka. ${ }^{9}$ berikut:

Ada beberapa jenis perpustakaan yaitu sebagai

\section{Perpustakaan Internasional}

Perpustakaan Internasional ialah perpustakaan yang bertanggung jawab atas pelestarian semua bahan pustaka yang diterbitkan di sebuah negara, perpustakaan Nasional ini berkedudukan di ibu kota negara Indonesia yang mempunyai jangkauan dan ruang lingkup secara nasional serta salah satu Lembaga Pemerintahan bukan Departemen (LPND) yang bertanggung jawab kepada Presiden.

\section{Perpustakaan Sekolah}

Perpustakaan sekolah ialah perpustakaan yang berada di lembaga pendidikan formal mulai lingkungan pendidikan dasar sampai menengah yang itu sebagai pusat belajar untuk mendukung tercapainya tujuan pendidikan.

\section{Perpustakaan Perguruan Tinggi}

Perpustakaan perguruan tinggi ialah perpustakaan yang terdapat pada perguruan tinggi, badan di bawahnya maupun lembaga yang setara dengan perguruan tinggi, dengan tujuan untuk membantu perguruan tinggi mencapai tujuannya.

\section{Perpustakaaan Umum}

Perpustakaan umum ialah sebuah perpustakaan yang didirikan oleh pemerintah daerah atau tertentu yang tersedia bagi masyarakat siapa saja yang ingin menggunakannya.

\section{Perpustakan Khusus}

Perpustakaan khusus ialah perpustakaan yang berada pada lembaga pemerintahan khusus dan swasta, seperti departemen, perusahaan dan lain-lain. Perpustakaan ini diadakan sebagai sumber informasi dan ilmu pengetahuan yang berkaitan langsung maupun tidak langsung dengan instansi induknya. ${ }^{10}$

\section{Perpustakaan Umum}

Menurut definisi yang diterima dalam IFLA General Conference Tahun 1985, perpustakaan umum merupakan sebuah perpustakaan yang didirikan dan dibiayai oleh pemerintah daerah, pemerintah pusat atau badan lain yang diberi wewenang untuk bertindak atas nama badan, tersedia bagi masyarakat siapa saja yang ingin menggunakannya tanpa ijin atau diskriminasi (IFLA 1986). ${ }^{11}$

Dalam Manifesto Perpustakaan Umum, UNESCO menyatakan bahwa perpustakaan umum sebagai pusat lokal informasi yang menyediakan semua jenis informasi dan pengetahuan bagi pengguna perpustakaan. ${ }^{12}$

\section{Ciri Perpustakaan Umum}

a. Terbuka untuk umum

b. Jasa yang diberikan bersifat cuma-cuma

c. Dibiayai dana umum atau dana yang berasal dari masyarakat, biasanya dikumpulkan melalui pajak dan dikelola oleh pemerintah

\section{Misi Perpustakaan Umum}

Menurut Manifesto perpustakaan umum di UNESCO, misi utama perpustakaan umum yang terkait dengan informasi, melek huruf, pendidikan dan kebudayaan sebagai berikut: ${ }^{13}$

a. Menciptakan dan memperkuat kebiasaan membaca dikalangan anak-anak sejak usia dini;

b. Membantu individual dan pendidikan swatindak serta pendidikan formal pada semua tingkat;

c. Menyediakan kesempatan bagi pengembangan kreasi pribadi;

d. Merangsang imajinasi dan kreativitas anak-anak dan kawula muda;

e. Membantu dan ikut serta dalam aktivitas dan program literasi bagi semua kelompok umur dan melalui aktivitas tersebut apabila diperlukan. ${ }^{14}$

\section{METODE PENELITIAN}

\section{Letak Penelitian}

Penelitian ini dilakukan di Perpustakaan umum Kecamatan Semanding yang tepatnya di desa Semanding Kecamatan Semanding Kabupaten Tuban. Perpustakaan 
ini didirikan untuk literasi atau budaya baca masyarakat Semanding yang di bawah naungan Dinas perpustakaan kabupaten Tuban.

\section{Metode Pengumpulan Data}

Metode dalam pengumpulan data yang digunakan adalah metode kualitatif yaitu wawancara dan pembagian angket atau kuesioner.

\section{Wawancara}

Wawancara merupakan sebuah proses atau kegiatan yang dilakukan oleh peneliti dengan memberikan pertanyaan kepada narasumber. Yang disini dilakukan peneliti mewawancarai atau bertanya kepada pustakawan yang ada di perpustakaan umum kecamatan Semanding.

\section{Kuesioner}

Kuesioner merupakan kegiatan pembagian angket atau beberapa pertanyaan yang ditulis peneliti dan disebarkan kepada responden yang dapat berupa pertanyaan tertutup (jawaban pilihan) atau pertanyaan terbuka (essay). Yang dalam hal ini peneliti membagikan angket dengan pertanyaan tertutup kepada 6 pengunjung yang ada di perpustakaan umum kecamatan Semanding.

\section{PEMBAHASAN}

\section{Peran Pustakawan Dalam Menarik Minat Baca}

Hasil dari wawancara dengan pustakawan yang ada di perpustakaan umum kecamatan Semanding tersebut mereka telah melakukan beberapa kegiatan untuk menarik minat baca ke perpustakaan umum kecamatan Semanding tersebut dari tingkat PAUD sampai SD dengan membuat lomba-lomba yang diikuti ditingkat PAUD dengan mewarnai, ditingkat TK dengan permainan fisik motorik seperti estavet tongkat, untuk tingkat SD kelas 1 sampai kelas 2 lomba menggambar, dan ada juga lomba mendongeng yang diikuti oleh guru KB, TK dan RA. Kemudian agenda yang dilakukan sampai hari ini adalah library tour yaitu kegiatan kunjungan ke perpustakaan yang sasarannya masih di tingkat TK yang dilakukan satu minggu dua kali di hari selasa dan kamis, dengan pihak perpustakaan memberikan surat pemberitahuan kepada lembaga TK dengan terlampir pula jadwal kunjungannya.

\section{Faktor-Faktor yang Mempengaruhi Minat Baca}

Membaca adalah suatu aktivitas yang setiap hari dilakukan. Baik membaca buku, majalah, internet atau yang lainnya. Dari Tersebarnya angket maka disimpulkan bahwa faktor yang membuat minat baca pada pengunjung terutama pada anak-anak adalah:

\section{Faktor Sosiologis}

Faktor ini menyangkut diantaranya lingkungan. Lingkungan merupakan hal yang sangat berpengaruh besar pada kehidupan seseorang, karena dari lingkungan itu kepribadian dan pola pikir seorang akan terbentuk dari lingkungan mulai dari anak-anak sampai dengan dewasa. Lingkungan yang baik akan membuat atau memberikan dorongan atau dampak positif untuk kehidupannya baik di masa sekarang maupun di masa depan. Begitu juga dengan sebaliknya apabila lingkungan tersebut kurang baik maka akan memberikan dorongan atau dampak negatif pula untuk kehidupan seseorang tersebut. Apalagi lingkungan keluarga atau rumah itu adalah lingkungan pertama dari seorang anak yang akan sangat berpengaruh besar dalam kehidupannya.

\section{Faktor Psikologis}

Faktor psikologis bisa dengan memotivasi seseorang dengan menceritakan pengalaman setelah membaca atau berkunjung ke perpustakaan, sehingga mempunyai minat untuk ikut ke perpustakaan untuk membaca dengan nyaman dan sesuai dengan gaya belajarnya sendiri serta menjadikan belajar itu sebagai kebutuhan. Selain itu bisa dengan membangun minat atau keinginannya untuk membaca dengan caranya masing-masing.

\section{KESIMPULAN DAN SARAN}

\section{Kesimpulan}

Dari hasil penelitian yang dilakukan diatas peneliti menyimpulkan bahwa:

Peran pustakawan di perpustakaan umum kecamatan Semanding tersebut sudah sedikit banyak menarik minat baca anak untuk datang ke perpustakaan.

Pelayanan yang diberikan oleh pustakawan harus lebih ditingkatkan lagi dari segi keramahan dan kenyamanan bagi pengguna.

Minat baca di daerah Semanding masih tergolong rendah. 


\section{Saran}

Bahan pustaka yang ada sebaiknya ditambah lagi dari buku bacaan sampai buku pengetahuan.

Peran pustakawannya perlu ditingkatkan kembali dengan cara kreatif dalam mengajak pengunjung untuk mencintai buku dan datang ke perpustakaan.

Sebaiknya bahan pustaka yang ada ditata dengan baik agar memudahkan pengunjung untuk menemukan buku atau bahan pustaka yang ingin dicarinya.

\section{DAFTAR PUSTAKA}

Prof. Dr. Tampubolon. 1993. Mengembangkan Minat Dan Kebiasaan Membaca Pada Anak, cetakan 1. Bandung: Angkasa.

Hariyanti, Dessy. Pembinaan minat baca.2016. Probolinggo: Diklat kepala perpustakaan probolinggo 7-13 April 2016.

Basuki, Sulistyo. Pengantar Ilmu perpustakaan.2014. (Edisi 1, cetakan 8). Tanggerang Selatan: Universitas Terbuka

Juhaeri. Kompetensi dan Etika Profesi Pustakawan. 2016. Probolinggo: Diklat kepala perpustakaan probolinggo 7-13 April 2016.

Suwarno, Wiji. 2014. Dasar - dasar ilmu perpustakaan, cetakan 4. Jogjakarta: Ar-ruzzz Media.

Sumiati, Opong. 2014. Pengelolaan Perpustakaan Sekolah (Edisi 1 Cetakan 1). Tanggerang Selatan: Universitas Terbuka.

Survey UNESCO, http://kominfo.belitungkab. go.id/2017/04/26/survey-unesco-minat-baca-orangIndonesia-terpuruk/,di akses 14 November 2019.

\section{ENDNOTES}

1 Mahasiswa Program S1 Ilmu Perpustakaan, Fakultas Ilmu Sosial dan Ilmu Politik, Jurusan Perpustakaan, Universitas Terbuka, Email: uswatunkhasanah@gmail. com

2 Survey UNESCO minat baca, http://kominfo. belitungkab.go.id/2017/04/26/survey-unesco-minatbaca-orang-Indonesia-terpuruk/

3 Prof. Dr. Tampubolon, "Mengembangkan Minat Dan Kebiasaan Membaca Pada Anak", (Bandung: Angkasa, 1993), cet. 1, hlm. 41.

4 Dessy Hariyanti, "Pembinaan minat baca", Diklat kepala perpustakaan probolinggo 7-13 April 2016, (Probolinggo, 2016), hlm. 120

5 Sulistyo Basuki, Pengantar Ilmu perpustakaan, Edisi 1(Tanggerang Selatan:Universitas Terbuka, 2014), Cet.8, hlm. 3.19

6 Juhaeri, "Kompetensi dan Etika Profesi Pustakawan", Diklat kepala perpustakaan probolinggo 7-13 April 2016, (Probolinggo, 2016), hlm. 140

7 Sulistyo Basuki, Pengantar Ilmu perpustakaan, Edisi 1(Tanggerang Selatan:Universitas Terbuka, 2014), Cet. 8 , hlm. 3.40

8 Wiji suwarno, " Dasar - dasar ilmu perpustakaan", (Jogjakarta: Ar-ruzzz Media, 2014), cet. 4, hlm. 11.

9 Opong Sumiati, "Pengelolaan Perpustakaan Sekolah", Edisi 1, (Tanggerang Selatan: Universitas Terbuka, 2014), Cet 1, hlm. 1.3.

10 Sulistyo Basuki, Pengantar Ilmu perpustakaan, Edisi 1(Tanggerang Selatan:Universitas Terbuka, 2014), Cet.8, hlm. 2.4

11 Ibid.,, hlm. 2.7

12 Ibid., hlm. 2.8

13 Ibid.,

14 Ibid.,hlm. 2.9 